\title{
BENGKEL MODIFIKASI CUSTOM DI KOTA BANJARMASIN
}

\author{
Eko Setiawan \\ Program Studi Teknik Arsitektur Fakultas Teknik Universitas Lambung Mangkurat \\ ekosetiawanarch@gmail.com \\ J.C. Heldiansyah \\ Program Studi Teknik Arsitektur Fakultas Teknik Universitas Lambung Mangkurat \\ jcheldiansyah@ulm.ac.id
}

\begin{abstract}
ABSTRAK
Perkembangan dalam dunia otomotif mengalami peningkatan setiap tahunnya, produsen otomotif khususnya sepeda motor bersaing membuat dan mengeluarkan jenis maupun merk dengan inovasi teknologi terbaru. Hal ini mendorong para pecinta modifikasi membuat dan menciptakan karya modifikasi. Kalimantan selatan memiliki potensi yang cukup besar dalam bidang otomotif khususnya bengkel modifikasi custom, permasalahannya adalah kurangnya jumlah bengkel dan fasilitas yang lengkap pada satu bengkel khususnya di kota Banjarmasin. Bengkel modifikasi custom di Banjarmasin jumlahnya sangat sedikit, selain itu juga memiliki banyak kekurangan dari segi fasilitas dan ciri khas bangunannya. Untuk menjawab permasalahan tersebut diperlukan suatu desain bengkel modifikasi custom yang memiliki fasilitas lengkap pada satu tempat dan memiliki ciri khas sebuah bangunan bengkel modifikasi agar dapat memberikan kenyamanan dan kemudahan bagi para pengunjungnya. Metode penyelesaian masalah yang diterapkan adalah metode Arsitektur Metafora yang mana nantinya unsur metafora akan diimplementasikan menjadi bentuk dan ruang pada bangunan. Konsep perancangan menerapkan konsep motor custom identity dimana hasil rancangan bengkel modifikasi custom tersebut terdiri dari beberapa karakteristik dan ciri khas dari sebuah motor custom.
\end{abstract}

Kata Kunci: Bengkel Otomotif, Modifikasi Custom, Bengkel Modifikasi

\begin{abstract}
The development in the automotive world is increasing every year, automotive manufacturers, especially motorcycles, compete to make and issue types and brands with the latest technology innovations. This encourages modification lovers to create and create modifications. South Kalimantan has considerable potential in the automotive field, especially custom modification workshops, the problem is the lack of complete workshops and facilities in one workshop, especially in the city of Banjarmasin. Custom modification workshop in Banjarmasin is very small in number, in addition it also has many shortcomings in terms of facilities and building characteristics. To answer these problems a custom modification workshop design is needed that has complete facilities in one place and has the characteristics of a modification workshop building in order to provide comfort and convenience for its visitors. The problem solving method applied is the Metaphor Architecture method, which later the metaphorical elements will be implemented in the form and space of the building. The design concept applies the concept of a custom identity motorcycle where the results of the custom modification workshop design consist of several characteristics and characteristics of a custom motorbike.
\end{abstract}

Keywords: Automotive Workshop, Custom Modification, Modification Workshop 


\section{PENDAHULUAN}

Peningkatan jumlah kendaraan bermotor sangat berpengaruh besar terhadap dunia otomotif sehingga Kendaraan bermotor jenis roda empat maupun roda dua terus meningkat setiap tahunnya. Kendaraan bermotor jenis roda empat ataupun roda dua seolah menjadi gaya hidup masyarakat perkotaan pada era modern ini khususnya roda dua. Produsen motor bersaing memunculkan desain baru yang dapat menarik minat konsumen dari berbagai macam kalangan di masyarakat, sehingga kendaraan roda dua begitu digemari dikalangan masyarakat. Disisi lain penjualan kendaraan jenis roda dua di Indonesia terus mengalami peningkatan dan juga penurunan setiap tahunnya, menurut data penjualan unit kendaraan jenis roda dua yang tercatat pada AISI (Asosiasi Industri Sepeda Motor Indonesia) dari 10 tahun kebelakang seperti yang tercantum sebagai berikut:

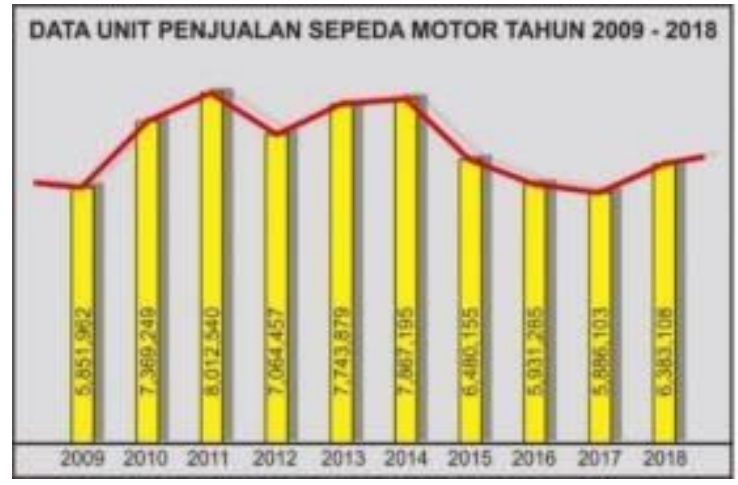

Gambar 1. Persentase penjualan sepeda motor indonesia

sumber : www.aisi.orid/statistic

Dari data di atas diketahui angka penjualan sepeda motor pada tahun 2018 sebesar 6,383,108 unit meningkat dari 2 tahun sebelum nya yang sempat menurun.

Kalimantan selatan khususnya kota Banjarmasin merupakan daerah yang sebagian banyak penduduknya menggunakan alat transportasi sebagai pilihan utama untuk bepergian baik dalam maupun luar kota.
Sebagian besar penduduk kota Banjarmasin menggunakan transportasi jenis roda dua, dikarenakan jenis transportasi ini lebih mudah dan efisien. Sebagian orang memilih jenis kendaraan roda dua ini karena harga yang cukup terjangkau dan lebih fleksibel untuk digunakan sehari-hari melihat kondisi jalanan di kota Banjarmasin yang mulai padat dan macet pada titik-titik tertentu.

Pada era modern ini, transportasi jenis roda dua selain untuk kebutuhan transportasi juga sebagai sarana menyalurkan kreatifitas maupun hobi bahkan menjadi gaya hidup bagi sebagian kalangan pecinta motor. Setiap orang memiliki selera terhadap jenis kendaraan roda dua yang mereka pilih dan memiliki jenis modifikasi masing-masing. Modifikasi khusus nya untuk jenis kendaraan roda dua banyak diminati mulai dari kalangan remaja sampai dewasa. Banyak diantara mereka memiliki kendaraan hasil modifikasi, dari yang hanya mengganti sebagian aksesoris atau biasanya disebut modif ringan maupun yang merubah total bentuk sepeda motor atau biasanya disebut modif berat.

Perkembangan modifikasi sepeda motor di Kalimantan selatan khususnya di kota Banjarmasin saat ini, menunjukkan peningkatan yang sangat tajam dan bahkan peningkatan yang terjadi bukan hanya dari segi kuantitas, tetapi juga dari segi kualitas hasil modifikasi yang dilakukan para modifikator. Hal ini dapat dilihat maupun disaksikan pada kontes-kontes yang sering diadakan, banyak inovasi terbaru yang dilakukan oleh para modifikator, banyak jenis motor yang dimodifikasi dengan berbagai model tren modif yang sedang berkembang. Ada berbagai jenis aliran modifikasi, salah satunya yang digemari maupun paling banyak peminatnya baik dari kalangan remaja maupun dewasa adalah jenis aliran modifikasi Custom atau nama lainnya adalah Old Skool, aliran modifikasi Custom merupakan konsep sepeda motor yang mengacu pada retro atau berkesan klasik. Modifikasi untuk motor klasik dengan menggunakan konsep retro modern, dengan menggunakan sparepart teknologi yang terbaru untuk motor keluaran lama. Kini, banyak para masyarakat umum maupun pecinta roda dua yang ingin memodifikasi 
sepeda motornya. Modifikasi bidang otomotif merupakan peluang bisnis yang sangat menjanjikan sekaligus penuh tantangan.

banyaknya keinginan untuk memodifikasi sepeda motor jenis custom ini membuat didirikannya bengkel-bengkel modifikasi sepeda motor jenis custom di kota Banjarmasin, baik bengkel resmi dari pabrikan maupun non pabrikan atau milik perorangan. Keberadaan bengkel-bengkel tersebut terus berkembang, yang mana tersebar di beberapa pelosok tempat di Banjarmasin.

Berdasarkan hasil pengamatan dan wawancara di lapangan, keberadaan bengkel-bengkel modifikasi aliran custom ini hanya terdapat beberapa saja dan tempatnya yang saling berjauhan, padahal antara bengkel satu dan lainnya memiliki hubungan dan saling membutuhkan dikarenakan bengkel-bengkel tersebut saling memiliki kekurangan dan kekurangan tersebut ada pada bengkel lainnya. Permasalahan yang didapat dari temuan fakta dilapangan seperti rata-rata bengkel memiliki fasilitas yang kurang lengkap dan kurang memadai, bangunan tidak memiliki ciri khas yang membuat sebagian orang susah dalam mencarinya dikarenakan bengkel-bengkel tersebut hanya memakai garasi rumah atau menyewa ruko, besar ruang yang terbatas juga menjadi alasan mengapa mereka membatasi jumlah pekerjaan modifikasi tersebut dan membuat pekerjaan bengkel tersebut dilakukan di halaman ruko maupun rumah.

Bengkel-bengkel tersebut memerlukan wadah yang dapat memfasilitasi kegiatan modifikasi mereka khususnya pada kota Banjarmasin yang penggunanya maupun peminat modifikasi tersebut semakin bertambah seiring waktu. Adapun diantaranya beberapa bengkel-bengkel tersebut juga seringkali digunakan sebagian komunitas motor yang terlibat sebagai tempat berkumpul sehingga diperlukannya fasilitas tambahan yang juga dapat mewadahi para komunitas modifikasi custom sebagai tempat berkumpul maupun bersosialisasi Bengkel modifikasi sepeda motor custom yang diharapkan bukan hanya sebagai bengkel modifikasi biasa, namun perlu adanya dukungan dari fasilitas lain agar membuat nyaman konsumen yang berkunjung ke dalam bengkel tersebut di samping untuk memodifikasi sepeda motornya.

Berdasarkan uraian di atas, permasalahan perancangan pusat oleh-oleh Kalimantan Selatan dirumuskan sebagai berikut: "Bagaimana rancangan sebuah Bengkel modifikasi custom di kota Banjarmasin yang dapat mewadahi kegiatan modifikasi pada satu tempat dan menjadi bangunan yang memiliki ciri khas modifikasi custom di kota Banjarmasin?

\section{TINJAUAN PUSTAKA}

\section{A. Tinjauan umum Bengkel}

Bengkel secara umum merupakan tempat perbaikan, perawatan serta pemeliharaan bagi alat dan mesin. Bengkel otomotif merupakan bengkel khusus yang melayani sepeda motor, mobil dsb. Untuk melakukan perbaikan, perawatan maupun pemeliharaan yang mana dilakukan oleh tenaga ahli mekanik. Menurut soedarma (2006) bengkel terbagi menjadi 2 yaitu bengkel repair shop dan bengkel body shop. Bengkel repair shop merupakan bengkel khusus yang melayani pekerjaan seperti perbaikan pada mesin kendaraan, rem, transmisi, ban, knalpot, dan pergantian oli, sedangkan bengkel body shop hanya melayani pekerjaan pada bagian body kendaraan seperti perbaikan terhadap kerusakan pada cat yang tergores atau lecet,body yang penyok serta body yang mengalami kerusakan akibat kecelakaan.

\section{Pengkasifikasian Bengkel Motor Secara Umum}

Bengkel sepeda motor secara umum terbagi atas beberapa jenis. Menurut lqbal (2004) bengkel secara umum dapat dibagi diantaranya sebagai berikut:

\section{a. Bengkel Umum Kendaraan Bermotor}

Bengkel umum kendaraan bermotor merupakan bengkel yang bertujuan untuk memperbaiki dan merawat kendaraan 
bermotor agar tetap memenuhi standar teknis dan layak untuk jalan.

\section{b. Bengkel Dealer Motor Resmi}

Bengkel resmi atau yang biasanya disebut dealer, merupakan bengkel khusus yang hanya melayani perbaikan, perawatan maupun pemeliharaan pada merek tertentu sesuai dengan merek pada kendaraan tersebut. Bengkel dealer maupun resmi sering kita temui disekitar kita seperti bengkel Yamaha, Honda, Suzuki, Kawasaki, Kymco dll.

\section{c. Bengkel Modifikasi}

Bengkel modifikasi merupkan bengkel yang melakukan perubahan-perubahan pada komponen kendaraan standar pabrik. Sebuah sepeda motor akan menjadi lebih bagus dan menarik setelah melakukan proses modifikasi baik dari segi tampilan maupun kecepatan.

\section{d. Bengkel Bubut}

Bengkel bubut merupakan bengkel yang dapat membuat atau menghasilkan komponen-komponen tertentu, contohnya seperti pembuatan sekrup, baut, as dan membentuk komponen baru dengan ukuran tertentu yang kadang-kadang ukurannya tidak standar atau sulit ditemukan, terutama di pasaran.

\section{e. Bengkel Listrik}

Bengkel listrik merupakan bengkel yang bertujuan untuk melakukan perbaikan pada alat-alat yang berhubungan dengan listrik, contohnya coil, dinamo, dan semua hal yang berhubungan dengan tenaga listrik.

\section{f. Bengkel Las}

Bengkel las merupakan suatu usaha penyedia jasa pengelasan berbagai macam jenis logam seperti menyambungkan beberapa logam yang terpisah.

\section{B. Tinjauan umum Modifikasi}

Modifikasi secara umum yaitu merubah bentuk suatu benda dari yang terlihat biasa menjadi terlihat menarik tanpa menghilangkan fungsi dasarnya. Menurut Setiawan (2007) pengertian modifikasi dapat diartikan sebagai upaya melakukan perubahan dengan penyesuaian-penyesuaian baik dalam segi fisik material (fasilitas dan perlengkapan) maupun dalam tujuan dan cara (metode, gaya, pendekatan, aturan serta penilaian). Dari pernyataan di atas pengertian modifikasi yaitu sebuah upaya dalam melakukan perubahan dengan cara penyesuaian baik dari segi fasilitas dan perlengkapan maupun dalam metode, gaya, pendekatan, aturan serta penilaian.

Menurut Soedarma (2006) jenis aliran modifikasi sepeda motor dapat diklasifikasikan sebagai berikut :

\section{a. Kelas Custom atau Old Skool}

Sepeda motor yang memiliki banyak aliran, gaya, macam-macam ornamen, dan bervariasi hasil akhirnya, aliran ini sering disebut, "Custom atau old skool" atau juga klasik. Sepeda motor custom kebanyakan bergaya retro maupun vintage dikarenakan gaya klasik tersebut enak untuk dilihat dan banyak diminati baik dari kalangan remaja maupun dewasa. Oleh karena itulah yang membuat banyak bengkel motor memilih sebagai bengkel modifikasi spesialis aliran custom, seperti Cafe Racer, Chopper, dan Bobber.

\section{b. Kelas Racing Style}

Motor jenis racing style atau yang disebut motor gaya balap merupakan sepeda motor sport yang biasa nya digunakan untuk balapan. Modifikasi jenis racing style ini kebanyakan di aplikasikan pada motor bebek dan matic dikarenakan jenis sepeda motor inilah yang sering digunakan sebagai ajang balap bagi para remaja.

\section{c. Kelas Extreme}

Motor kelas Extreme merupakan motor yang pada umumnya bernilai mahal dari puluhan juta hingga ratusan juta rupiah. Sepeda motor kelas extreme biasanya sudah memiliki desain yang menyerupai motor hasil modifikasi yang 
berbeda dari bentuk sepeda motor standar pada umumnya, sehingga proses modifikasi tambahan yang biasanya dilakukan hanya sedikit.

Jenis peralatan yang terdapat pada bengkel khusus modifikasi custom pada dasarnya sama dengan peralatan bengkel pada umumnya, akan tetapi ada beberapa tambahan lainnya, seperti:

\begin{tabular}{lc}
\multicolumn{1}{l}{$\begin{array}{l}\text { Jenis Peralatan } \\
\text { Tool box }\end{array}$} & Dimensi P $\times L \times T$ \\
Rak barang & $0.5 \mathrm{~m} \times 2 \mathrm{~m} \times 1 \mathrm{~m}$ \\
Stopper kendaraan & $0.5 \mathrm{~m} \times 2 \mathrm{~m} \times 2 \mathrm{~m}$ \\
Lifter/dongkrak & $0.3 \mathrm{~m} \times 0.2 \mathrm{~m} \times 0.5 \mathrm{~m}$ \\
Post lift motor & $0.3 \mathrm{~m} \times 0.2 \mathrm{~m} \times 0.2 \mathrm{~m}$ \\
Compressor & $1.9 \times 5.5 \mathrm{~m}$ \\
Gas blower & $0.3 \mathrm{~m} \times 0.5 \mathrm{~m} 0 \times 0.2 \mathrm{~m}$ \\
Mesin press hidrolik & $0.2 \mathrm{~m} \times 0.1 \mathrm{~m} \times 0.1 \mathrm{~m}$ \\
Mesin las & $0.3 \mathrm{~m} \times 0.2 \mathrm{~m} \times 1.5 \mathrm{~m}$ \\
Mesin bubut & $0.3 \mathrm{~m} \times 0.2 \mathrm{~m} \times 0.2 \mathrm{~m}$ \\
Scraper & $3 \mathrm{~m} \times 0.5 \mathrm{~m} \times 1.5 \mathrm{~m}$ \\
Milling & $2 \mathrm{~m} \times 0.5 \mathrm{~m} \times 1.5 \mathrm{~m}$ \\
\hline
\end{tabular}

Gambar 2. Peralatan Bengkel Modifikasi Sumber: Penulis 2019

\section{METODE PERANCANGAN}

Metode yang dipilih untuk menyelesaikan masalah pada rancangan adalah pendekatan secara metafora. Faktor pemilihan metode Metafora tersebut berdasarkan identitas atau karakter pembentuk modifikasi custom tersebut lalu diimplementasikan kedalam bangunan dari segi exterior dan interior pada bangunan. Metafora yang dipilih pada rancangan adalah metafora Intangible. Metafora intangible atau yang sering disebut metafora abstrak yaitu metafora yang berasal dari abstrak atau tidak terlihat (tidak secara bentuk). Metafora abstrak dapat berasal dari sebuah ide, konsep, gagasan dan paham seseorang seperti budaya, naturalism, komunikasi dan tradisi.

\section{PEMBAHASAN}

\section{A. Konsep Program}

Tujuan dalam perancangan Bengkel modifikasi custom di kota Banjarmasin ini diharapkan dapat mengakomodasi segala kegiatan modifikasi sepeda motor custom didalamnya dengan berbagai fasilitas pendukung agar memberi kenyamanan dan kemudahan bagi para pengunjung dan menjadikan bangunan yang memiliki ciri khas dari modifikasi custom itu sendiri agar memudahkan para pengunjung dalam mencari bangunan bengkel tersebut. Maka dari itu, konsep program yang digunakan adalah konsep motor custom identity.

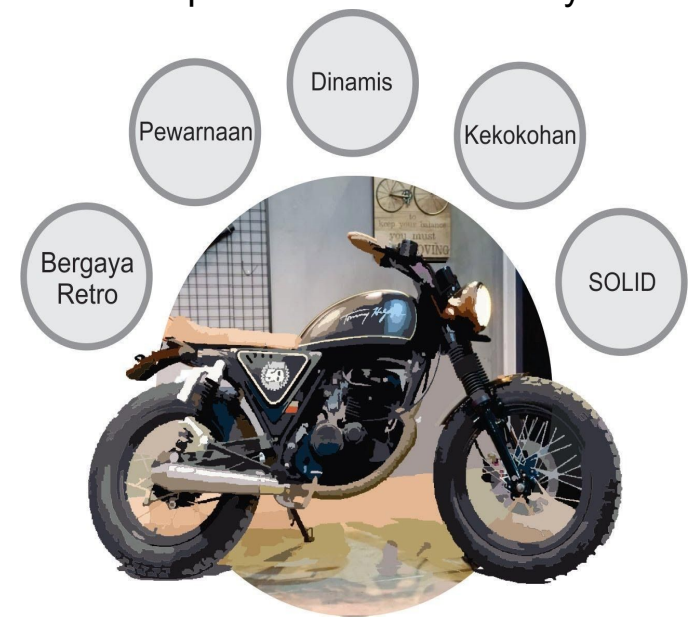

Gambar 3. Konsep Custom Identity Sumber: Penulis 2019

Motor custom identity merupakan identitas sebuah sepeda motor custom yang dapat dibentuk melalui ciri khas atau karakteristik motor custom itu sendiri, peranannya dapat bertujuan agar menjadikan bangunan yang memiliki ciri khas dan berbeda, dikarenakan bengkel modifikasi custom itu berbeda dengan bengkel umum lainnya. Identitas motor custom dapat diuraikan seperti di bawah:

Karakter pembentuk identitas pada motor custom yang pertama ialah motor custom 
bergaya retro, vintage, ataupun klasik yang bagus dilihat kapan saja, bahkan tidak hilang oleh waktu dan juga bisa dikombinasikan dengan gaya motor masa kini. Pemilihan warna pada motor custom memiliki makna yang dalam seperti, warna hitam memiliki makna kekokohan, warna merah memiliki makna keberanian sebuah sepeda motor custom kebanyakan memilih warna-warna gelap untuk warna pada sepeda motornya. Motor custom memiliki gaya gerak yang dinamis ketika dikendarai, rangka-rangka pada sepeda motor custom yang dibiarkan terekspos agar memperlihatkan kekokohan pada motor custom itu sendiri, sampai material yang digunakan pun berkesan solid dan kuat.

\section{B. Penerapan Metafora dalam Desain}

Metafora dalam desain yang dimaksud adalah metafora yang diterapkan dalam rancangan awalan bangunan berupa gubahan bangunan bentuk awal bangunan. Gubahan bentuk awal bangunan terinspirasi dari bentukan dua buah sepeda motor yang dilakukan beberapa transformasi terhadapnya. Transformasi tersebut bermulai dari bentukan dua buah sepeda motor yang sedang melakukan gerak dinamis ketika sedang berbelok, kemudian dilakukan penggabungan, pemotongan, dan peninggian sehingga menghasilkan sebuah gubahan bentuk bangunan bengkel modifikasi tersebut. (Gambar 4).

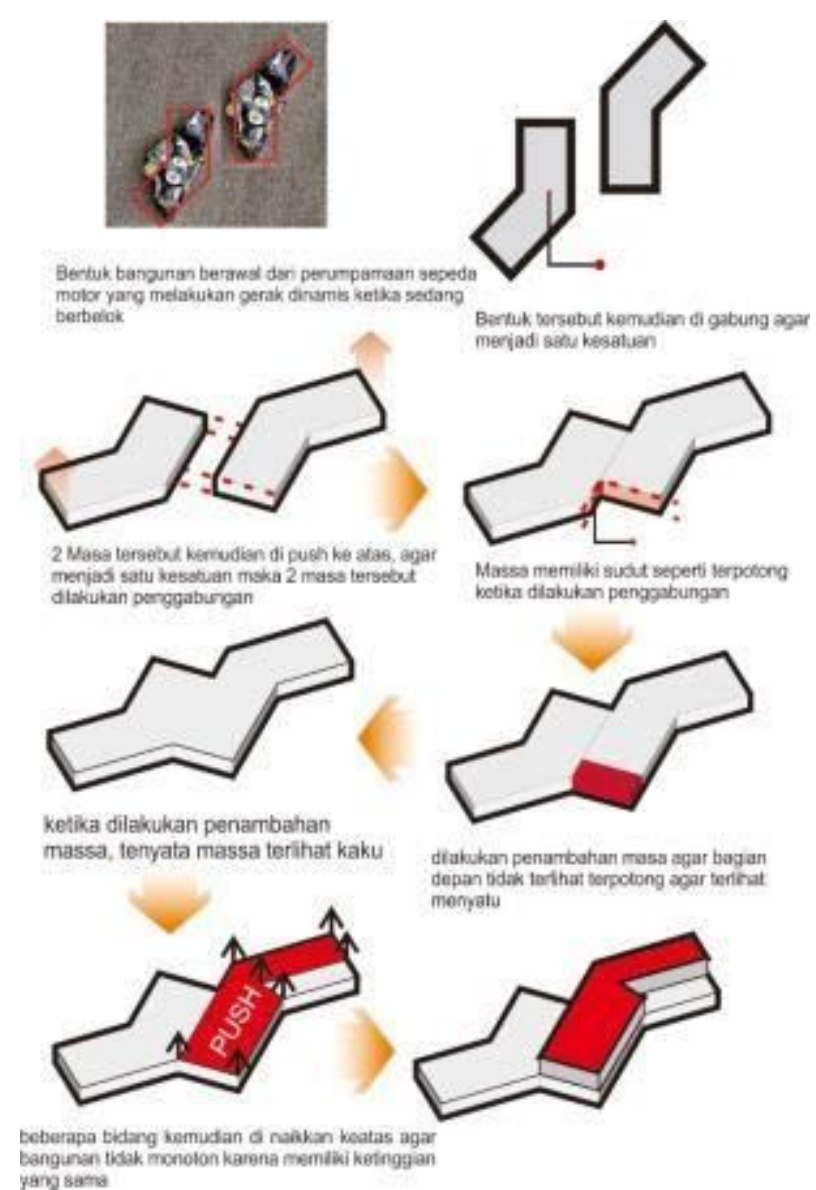

Gambar 4. Metafora Bentuk Dasar Bangunan Sumber: Analisis Pribadi 2019

Metafora berikutnya juga diterapkan dalam desain fasade bangunan, yang mana keseluruhan fasade bangunan terinspirasi dari hal-hal yang berkaitan dengan sepeda motor pula, yang mana lebih mengarah kepada mulai dari sifat hingga fisik dalam sepeda motor. Tujuan dari metafora terhadap fasade tersebut adalah untuk semakin memunculkan karakteristik dari bangunan Bengkel Modifikasi Custom di Banjarmasin. Beberapa detail fasade yang sesuai dengan karakternya masing-masing dapat kita lihat pada gambar berikut. 


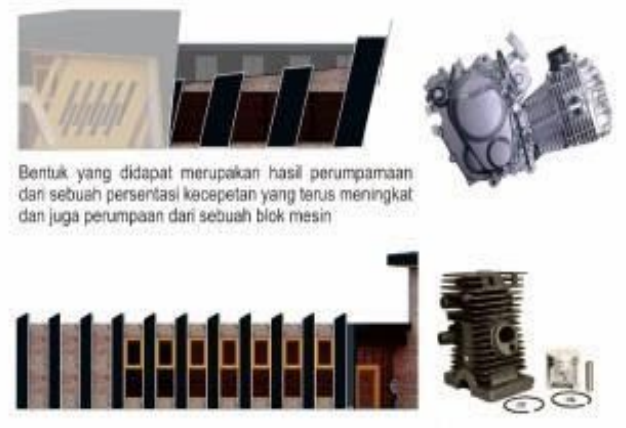

massa yang berlungsi sebagai bangunan zona private maka jika dilbaratkan pada bagian motor merupakan mesinnya dikarenakan bagian tersebut merupakan bagian penting agar berjalannya sisteml tersebut fasade yang digunakan pun berupa perumpamaan garis dari kisi-kisi sebuah blok mesin

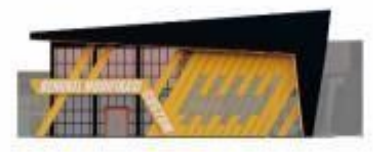

massa yang berawal dari bentuk persegi yang di bangun kemudian mendapatkan perubahan dan penambahan bentuk sebagaimana sebuah motor yang melakukan modifikasi

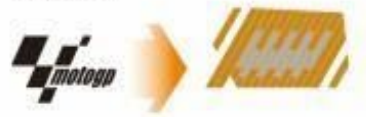

Fasade depan bangunan merupakan perumpamaan bentuk bendera moto $\mathrm{gp}$ yang disederhanakan dan mendapatkan modifikasi bentuk

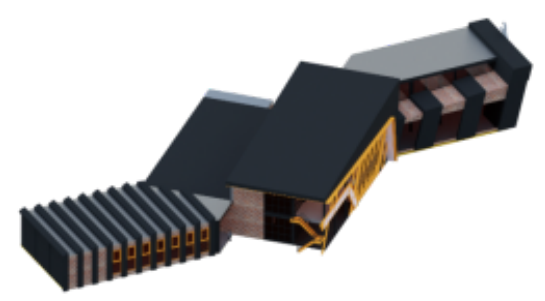

Warna hitam sangat dominan pada bangunan dikarenakan warna hitam merupakan warna yang biasa diterapkan pada sepeda motor custom yang memiliki makna kekokohan.

Pemilihan warna orange sebagai titik berat warna pada bangunan, warna yang mencolok seperti orange seringkali menjadi pilihan untuk sepeda motor custom dikarenakan warna nya yang mencolok dan enak untuk dilihat

Batu bata expose juga menjadi pilihan warna pada bangunan agar memberikan kesan retro atau vintage pada bangunan

Gambar 5. Transformasi Detail Facade Sumber: Analisis pribadi 2019

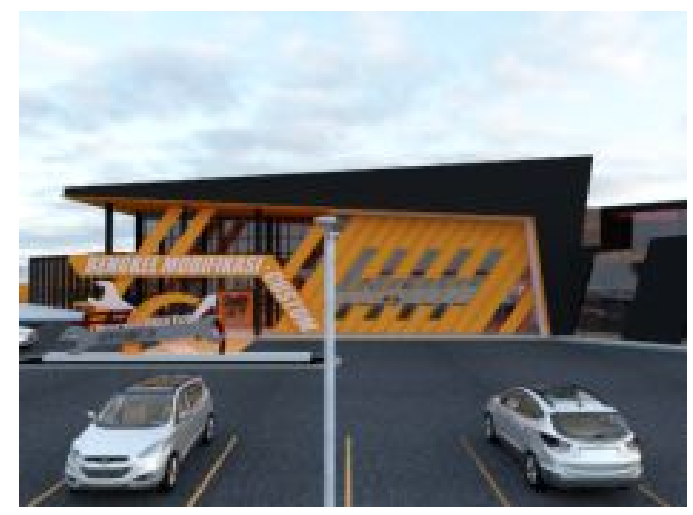

Gambar 6. Detail Fasade Bangunan Sumber: Penulis 2019

\section{Penerapan Konsep Custom Identity}

Sesuai dengan yang telah dijabarkan sebelumnya, pemilihan warna pada konsep motor custom identity cenderung mengarah kepada warna gelap khususnya hitam yang memiliki makna kekokohan dan orange sebagai titik berat. Rancangan bangunan Bengkel Modifikasi Custom di kota Banjarmasin menggunakan warna hitam terutamanya pada bagian struktur utama yang mendominasi pada rancangan dan terekspos cukup jelas baik pada eksterior maupun interior bangunan. Selain itu, motor custom juga terkesan mengekspos rangka-rangkanya guna memperlihatkan kekuatannya, yang mana juga diterapkan ke dalam rancangan yang mengekspos struktur-struktur bangunan khusus nya utilitas dan diikuti dengan penggunaan material kaca khusus nya pada area bengkel, penjualan dan pelayanan (Gambar 7). Bengkel Modifikasi Custom di Banjarmasin juga dilengkapi oleh beberapa fasilitas penunjang seperti penjualan aksesoris, kelengkapan berkendara, merchandise, cafe, tempat berkumpul para komunitas guna semakin meramaikan aktivitas yang ada didalamnya. Ruang-ruang tersebut dirancang sedikit berbeda dari ruang bengkel pada umumnya, yang mana dirancang dengan menggunakan warna yang sedikit lebih natural, yaitu dominasi coklat 
muda hingga tua dan beberapa juga menggunakan batu bata expose sehingga memberikan kesan vintage pada bangunan, area khusus yang memberikan kesan vintage adalah area café (gambar 10), dikarenakan area café lah yang sering ramai khusus nya oleh anak muda maupun komunitas. Desain ruang yang lain mengacu kepada area bengkel dan café agar tidak berbeda dalam segi desain dan warna, ruang-ruang tersebut tentunya juga didukung oleh perabot-perabot dengan bentuknya yang menyesuaikan fungsi ruang masing-masing. Untuk lebih jelasnya mengenai penerapan konsep motor custom identity kedalam interior bangunan dapat kita lihat pada gambar berikut.

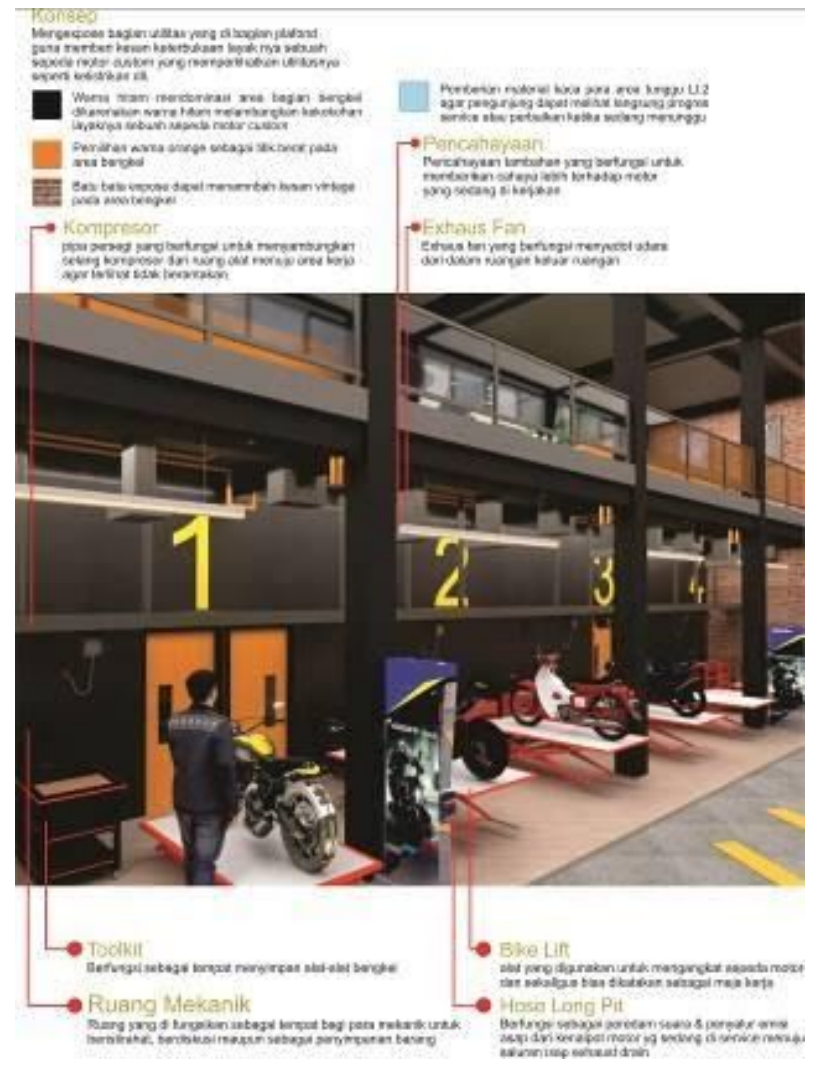

Gambar 7. Interior Lantai 1: Area Bengkel Modifikasi

Sumber: Penulis 2019

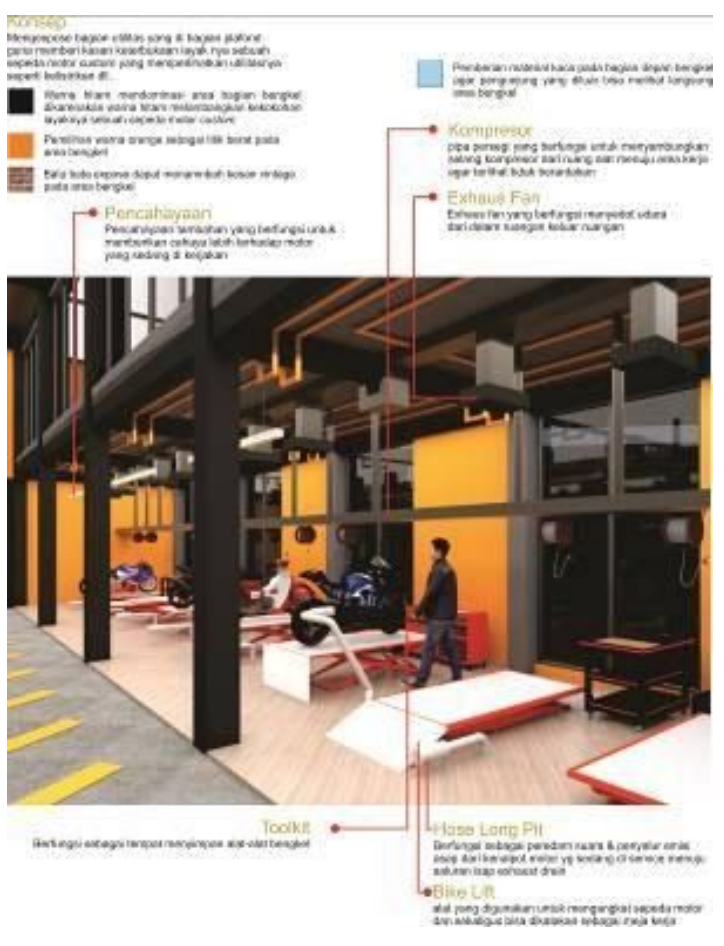

Gambar 8. Interior Lantai 1: Bengkel service Sumber: Penulis 2019

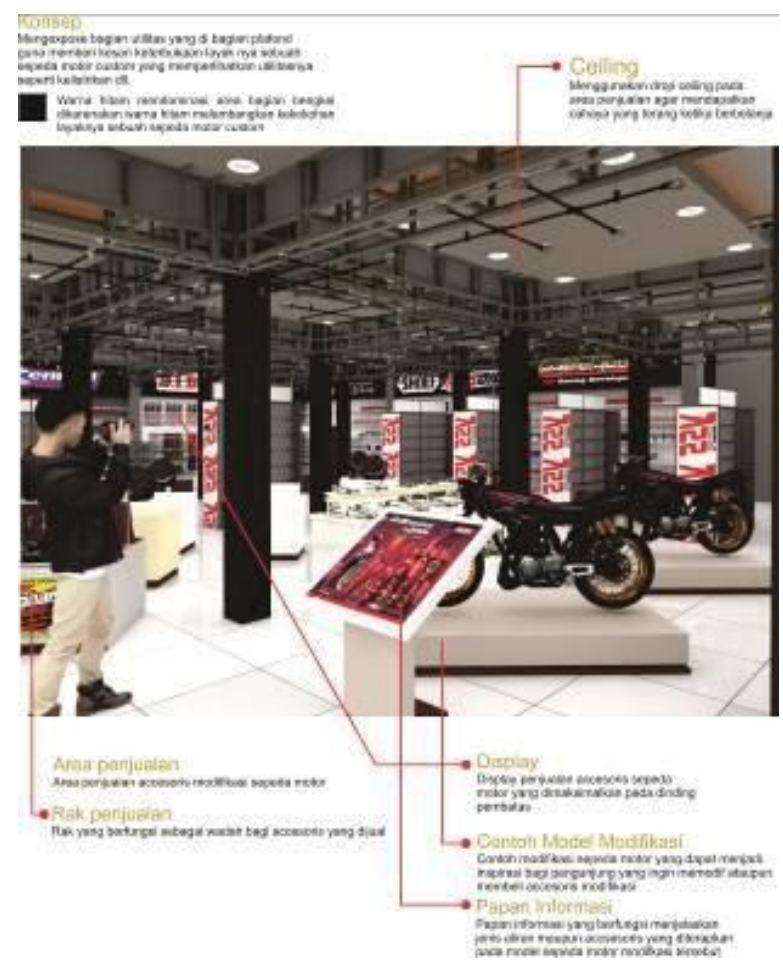

Gambar 9. Lantai 1: Area Penjualan

Sumber: Penulis 2019 


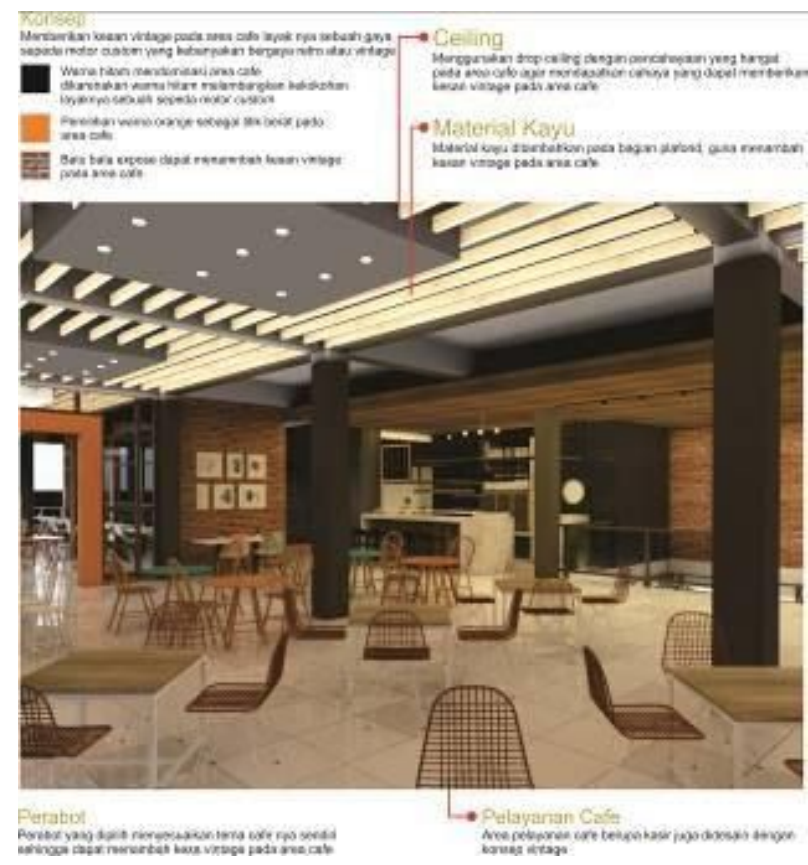

Gambar 10. Lantai 2: Area Café indoor Sumber: Penulis 2019

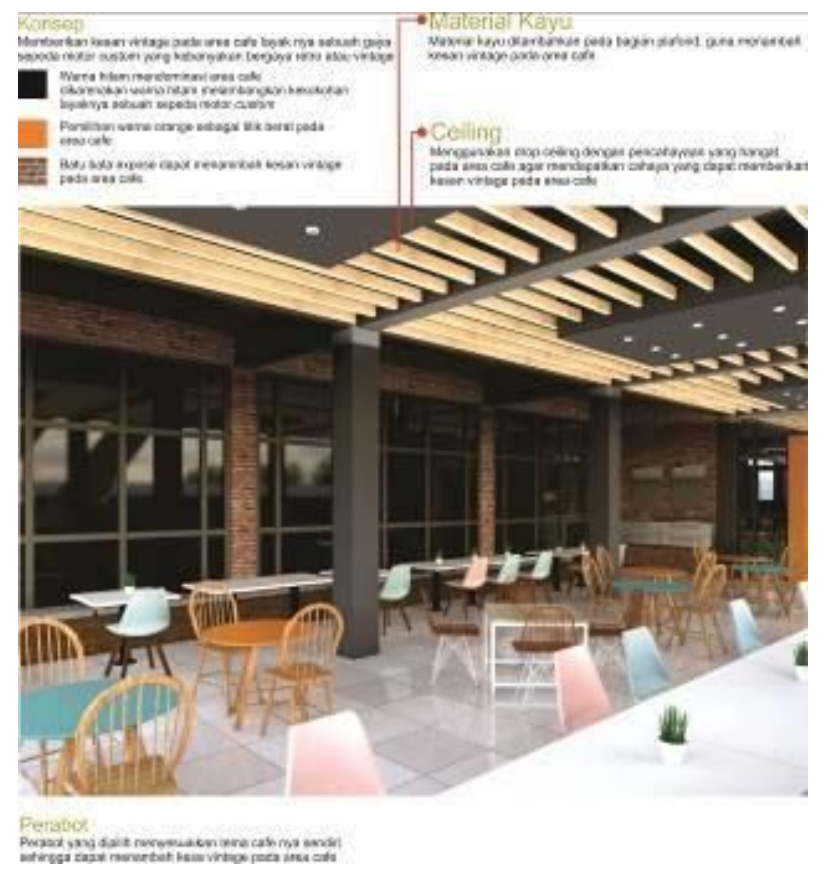

Gambar 11. Interior Lantai 2: Café Outdoor Sumber: Penulis 2019
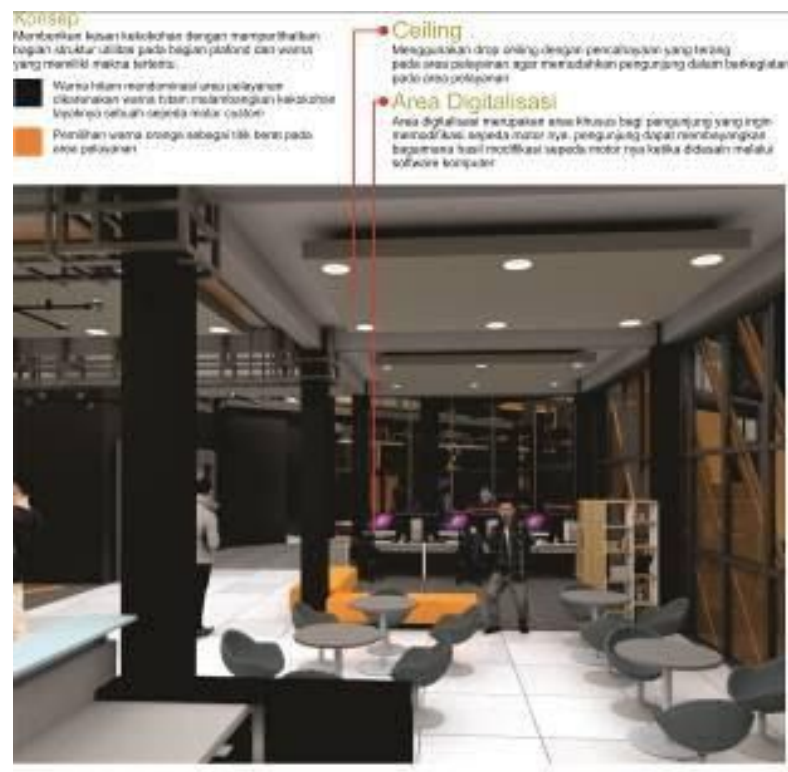

Anesa pelsyanan

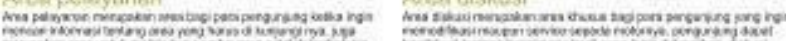

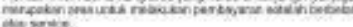

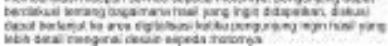

Gambar 12. Lantai 1: Area Pelayanan Sumber: Penulis 2019
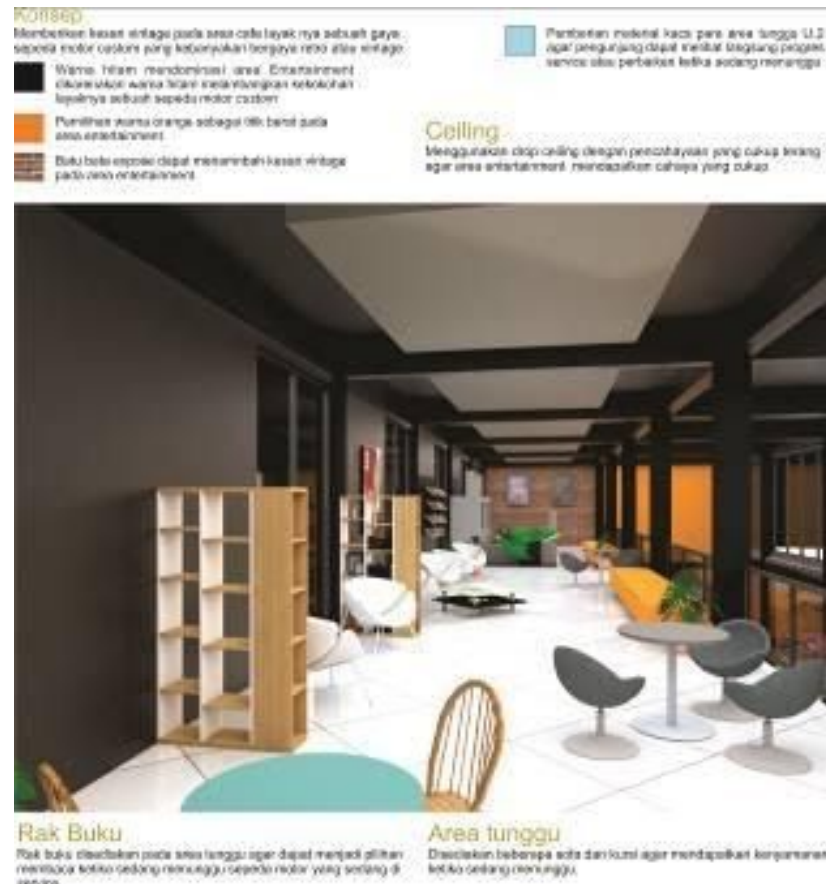

Gambar 13. Lantai 2: Area tunggu Sumber: Penulis 2019 


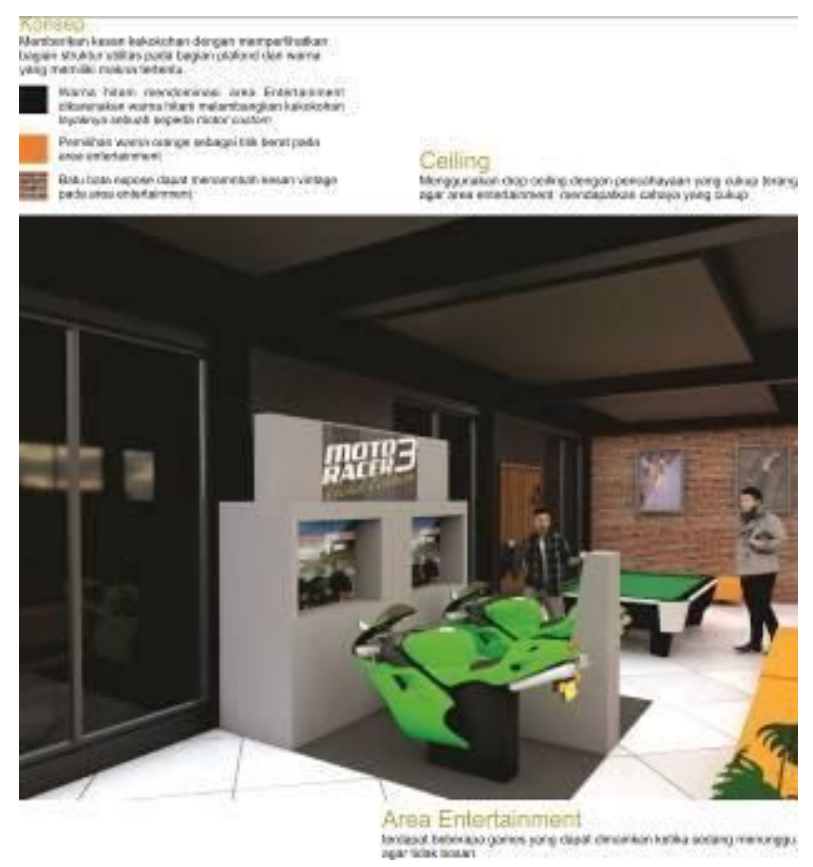

Gambar 14. Lantai 2: Area Entertainment Sumber: Penulis 2019

\section{PENUTUP}

Bengkel Modifikasi Custom di kota Banjarmasin dirancang karena belum tersedianya tempat yang dapat mewadahi kegiatan modifikasi custom pada satu tempat dan menyediakan fasilitas lengkap dalam satu bangunan. Modifikasi jenis custom dipilih dikarenakan perkembangannya yang pesat dan jumlah peminatnya yang semakin bertambah setiap tahunnya, bukan hanya fasilitas bengkel modifikasi saja yang tersedia pada rancangan ini, melainkan dilengkapi dengan fasilitas penunjang berupa penjualan aksesoris, kelengkapan berkendara, merchandise, kafe, tempat berkumpul para komunitas dan berbagai hiburan lain agar memberikan kemudahan dan kenyamanan bagi pengunjungnya. Setelah melakukan penerapan konsep Motor Custom Identity pada rancangan Bengkel Modifikasi Custom di kota Banjarmasin diharapkan rancangan dapat memiliki ciri khas karena implementasi dari ciri khas ataupun karakteristik pembentuk identitas motor custom itu sendiri sehingga dapat mempermudah bagi sebagian pengunjung dalam mencarinya serta memberikan kemudahan dan kenyamanan bagi pengunjung dalam memodifikasi motor custom dikarenakan tersedianya tempat yang lengkap dan didukung oleh fasilitas tambahan lainnya khususnya di kota Banjarmasin.

\section{HASIL DESAIN}

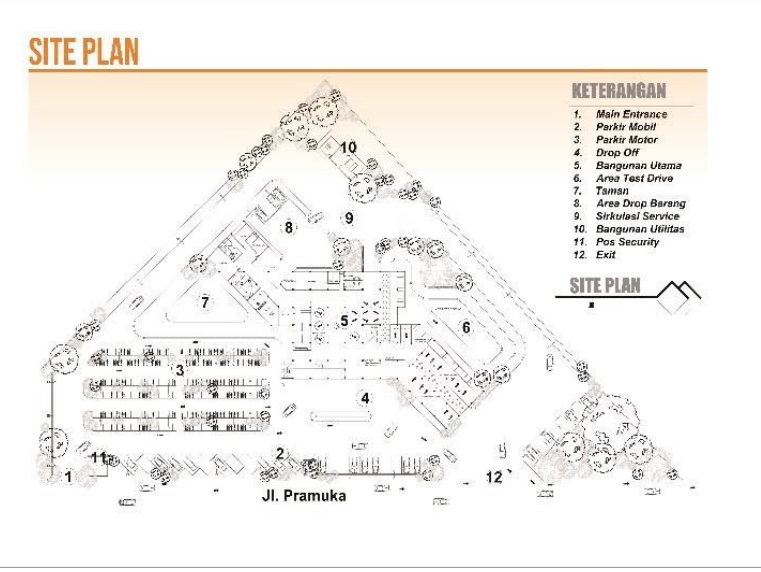

Gambar 15. Rencana Tapak Bangunan Sumber: Penulis 2019

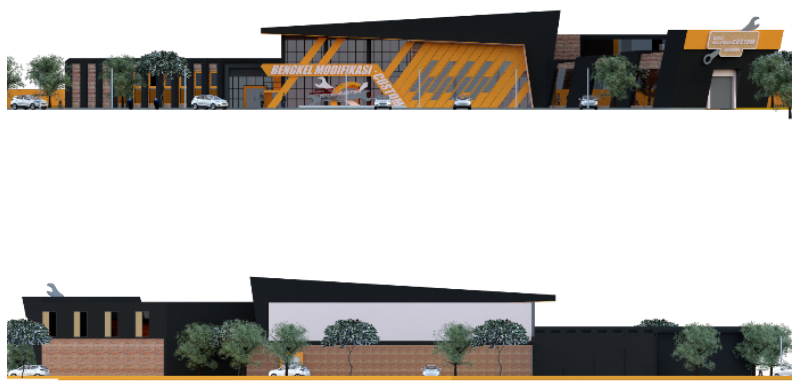

Gambar 16. Tampak Depan dan Belakang Sumber: Penulis 2019 


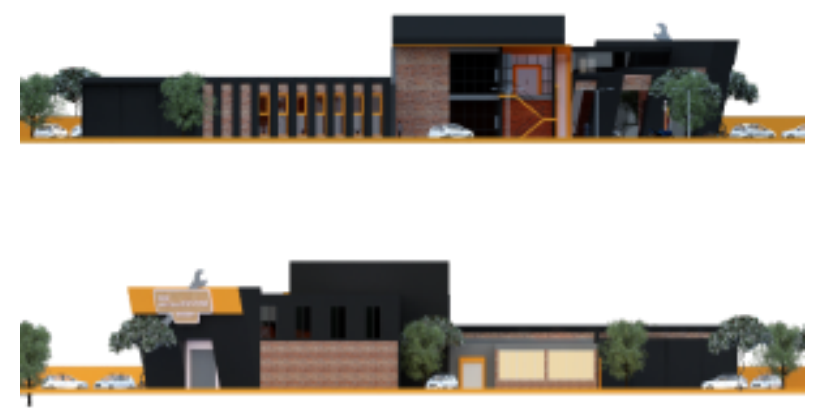

Gambar 17. Tampak Samping

Sumber: Penulis 2019
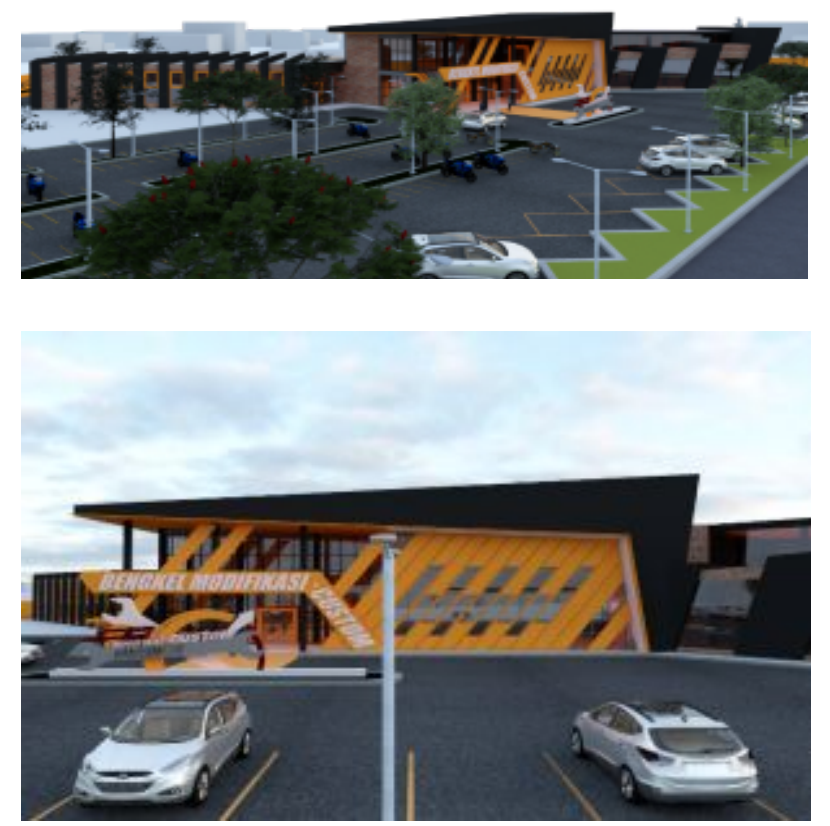

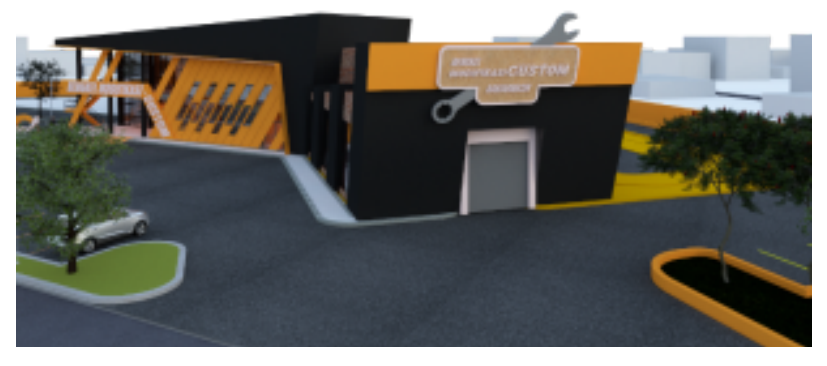

Gambar 18. Perspektif Eksterior

Sumber: Penulis 2019

\section{DAFTAR PUSTAKA}

AISI. Asosiasi Industri Sepedamotor Indonesia: $\quad$ Statistic. 2019. https://www.aisi.or.id/statisticl.

Broadbent. (1988). Arsitektur Metafora. Arsitektur Metafora.

Setiawan. 2007. Pengertian Modifikasi Sepeda Motor. http://info-dunia-maya.blogspot.co.id/2 013/03/pengertian-dan-definisi-jenis-m otor.html.

Soedarmo, H. 2008. Panduan Praktis Merawat dan Memperbaiki Sepeda Motor. Jakarta: Gramedia.

Iqbal. 2004. Mendongkrak Kinerja Bisnis Bengkel Roda 4 \& Roda 2. Jakarta: Gramedia.

Soedarmo, H. dan A. Kurniawan. 2006. Menjadi Kaya dengan UKM Otomotif Roda Dua. Depok: Kawan Pustaka. 